\title{
Does preoperative anxiety felt by patients requested to participate in clinical trials related to general anesthesia before elective surgery depend on temperament?
}

\author{
Jae Hoon Oh, Woo Jong Shin, Suin Park, and Kyoung Hun Kim \\ Department of Anesthesiology and Pain Medicine, Hanyang University College of Medicine, Seoul, Korea
}

\begin{abstract}
Background: Preoperative anxiety may differ according to patient temperament. It will be increased when patients are requested to participate in a study involving anesthesia. The purpose of this study was to show that the anxiety felt when patients are requested to participate may differ according to temperament in both patients who agree and disagree to participate.

Methods: Three hundred and twenty-one patients over age 18 with American Society of Anesthesiologists 1 and 2 completed a survey questionnaire. The degree of anxiety was measured according to patient temperament. It was compared on the basis of the State-Trait Anxiety Inventory (STAI) and visual analogue scale (VAS).

Results: In the agreed group, the degree of anxiety measured by "usual, present STAI" and VAS in the monitors (those who want to know as much as possible about anesthesia and surgery) was significantly higher than that in the blunters (those who want to know as little as possible) ( $\mathrm{P}=0.041$ for the "usual STAI," 0.017 for "present STAI," and 0.001 for VAS, respectively). Among patients with a lower educational level, the numbers of blunters and monitors were 57 (79\%) and 32 (59\%), respectively, indicating that the ratio of blunters was significantly higher $(P=0.026)$.

Conclusions: Both traits of patients in each group were influenced by psychological burdens. The anxiety of the monitors who agreed to participate was significantly higher than that of blunters. In addition to temperament, education level affects participation. Obtaining consent for participation by understanding temperament and considering factors that may reduce the participation rate will be required.
\end{abstract}

Key Words: Anxiety, Clinical trial, Psychological stress.

Corresponding author: Woo Jong Shin, M.D., Ph.D.

Department of Anesthesiology and Pain Medicine, Hanyang University Guri Hospital, 153, Gyeongchun-ro, Guri 11923, Korea

Tel: 82-31-560-2400, Fax: 82-31-563-1731

Email:swj0208@hanyang.ac.kr

ORCID: http://orcid.org/0000-0002-3786-2267

Received: December 12, 2016.

Revised: January 12, 2017 (1st); February 7, 2017 (2nd).

Accepted: February 16, 2017.

Korean J Anesthesiol 2017 June 70(3): 277-291

https://doi.org/10.4097/kjae.2017.70.3.277

\section{Introduction}

Prior to elective surgery, many patients report anxiety related to the surgery and anesthesia [1]. Such anxiety is affected by a patient's temperament or character, disease, and level of understanding regarding surgery and anesthesia, and the degree of the anxiety is dependent on individual patient sensitivity [2]. Patient anxiety may be further increased, particularly in a clinical trial involving anesthesia, if the patients have insufficient medical knowledge regarding the surgical procedure and the specific conditions of the anesthesia. The anxiety that patients may feel

(c) This is an open-access article distributed under the terms of the Creative Commons Attribution Non-Commercial License (http://creativecommons.org/ licenses/by-nc/4.0/), which permits unrestricted non-commercial use, distribution, and reproduction in any medium, provided the original work is properly cited. 
when they are requested to participate in a clinical study by a medical staff member providing anesthesia in an operative situation is dependent on the patient's temperament, disease, and degree of understanding regarding the disease or the surgery $[3,4]$. Severe anxiety may cause not only sympathetic nervous system stimulation that may lead to increased blood pressure, but also increased incidence of tachycardia and arrhythmia during the induction of anesthesia, increasing the demand for an anesthetic [1]. Such anxiety is a critical factor in a patient's decision regarding whether or not to participate in a clinical research study. Hence, it is important to investigate various factors relating to participation in clinical studies.

Consistent with the recent trend toward increased social interest in patients' rights, it is necessary to inform patients of their right to refuse to participate in a clinical study and to provide detailed explanation of a clinical study in order to avoid participation of any patients that is not based on sufficient understanding and voluntary consent with respect to the purposes, methods, and expected adverse effects of the study, as well as to ensure protection of a subject's human rights.

Recently, Moerman et al. [5] classified patient temperaments with reference to two items related to the desire to learn about surgery and anesthesia. Patients may be classified as "monitors," who prefer to gain knowledge regarding the relevant information when they are confronted with a stressful situation, such as a surgery, or as "blunters," who prefer not to gain knowledge regarding such information [6]. Before an elective surgery, providing a great deal of information about the surgery helps to diminish preoperative anxiety in the former type of patients, while giving as little information as possible, with the exception of necessary details, better aids in diminishing preoperative anxiety in the latter type of patients. Providing a large amount of information regarding a particular surgery to all patients, regardless of the patients' temperament, may increase rather than decrease the anxiety in "blunters." Furthermore, just as providing ample information about a surgery may increase the preoperative anxiety of a patient depending on the patient's temperament, providing a patient with detailed explanation regarding participation in a clinical study may also increase the preoperative anxiety. The purpose of the present study was to show that the anxiety felt by patients when they are requested to participate in a clinical study related to anesthesia may differ according to patient temperament, as classified by Moerman et al. [5], in both groups of patients.

\section{Materials and Methods}

\section{Study population}

After acquiring approval from the Institutional Review Board
(2012-05-023), 321 adult patients over the age of 18 with American Society of Anesthesiologists (ASA) physical status class 1 or 2 prior to elective surgery were visited one day before the operation and completed a survey questionnaire (Appendix), after they had been given an explanation of the clinical study described in detail in the survey questionnaire and had consented to participation.

\section{Study design and protocol}

\section{Survey questionnaire}

The returned questionnaires were reviewed, and 310 questionnaires were analyzed, following the exclusion of questionnaires with missing responses (Fig. 1). Responding to the questionnaire took less than 30 minutes in all patients in stable condition. The patients experienced no particular difficulties in understanding the questions included in the questionnaire. The patients were assured that they would not be disadvantaged even if they did not consent to participate, and that they could withdraw from the study at any time. In the present study, patient consent was obtained by one senior anesthesia resident who was not involved in the clinical study, had no personal relationship with the patients, and was aware of all the information regarding the clinical study. The confidentiality of personal information was protected, and attention was paid to reduce any physical or mental effects.

\section{Usual State-Trait Anxiety Inventory (STAI)}

The patients were requested to choose one response for each of the individual questions of the "usual STAI" developed by Grös et al. [7].

Patient characteristics and temperament classified by the Amsterdam Preoperative Anxiety and Information Scale (APAIS)

Then, the patients were asked to provide basic information about themselves. Scores for the APAIS were obtained according to the degree of anxiety that the patients felt regarding the anesthesia and the surgery, as well as their desire to learn about the anesthesia and the surgery. The APAIS questionnaire consists of six questions, including four items about the anxiety felt by patients in relation to the anesthesia and surgery, and two items about the desire to learn. The four items related to anxiety were rated on a scale from 1 to 5 , with the total score ranging from 4 to 20 points. A higher score indicated a higher level of anxiety. The scores for the two items regarding the desire to learn about the anesthesia and surgery were added up to range from 2 to 10 points. Patients with a score from 2 to 4 points were classified as "blunters," who do not want to learn about the anesthesia and surgery or who want to learn as little as possible. Patients with 


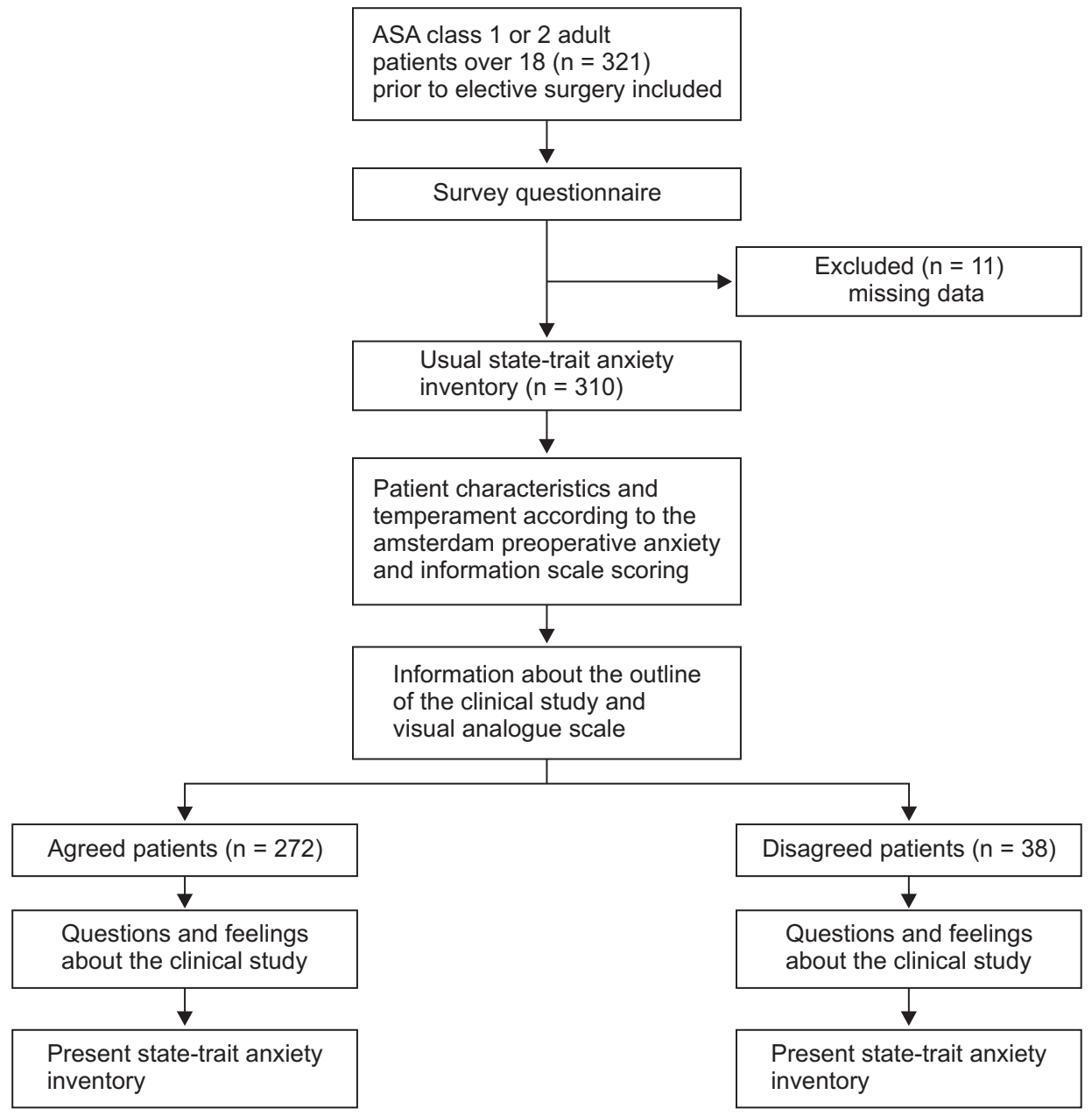

Fig. 1. Flow diagram of the survey questionnaire. ASA: American Society of Anesthesiologists. a score from 8 to 10 points were classified as "monitors," who want to learn as much as possible about the anesthesia and surgery. Patients with a score from 5 to 7 points were classified as "non-monitors and non-blunters."

\section{Information about the outline of the clinical study and visual analogue scale (VAS)}

The following items of the questionnaire provided information regarding the outline of the clinical study in which the patients could participate; the specific methods; the inhalation anesthetics utilized, with their pros and cons; and the intravenous anesthetics utilized, with their pros and cons. Next, the patients were requested to indicate the degree of anxiety they felt at the time of the request to participate in the clinical study, according to the VAS.

\section{Questions and feelings regarding the clinical study}

The patients were requested to rate their level of understanding of the information provided, their thoughts about the clinical studies implemented in South Korea, the specific feelings and degree of anxiety they felt when they were requested to participate, and their reasons for the decision to participate in the clinical study.

\section{Present STAI}

The degree of anxiety patients felt was rated using the preoperative "present STAI." The STAI questionnaire, which is the most frequently used anxiety self-rating method, consists of 20 questions to measure the present or usual anxiety, considering the patient's temperament and situation. Each question is used to rate the degree of anxiety in the present situation on a scale from 0 to 3 points, for a maximum total score of 60 points.

Considering patient temperament classified by the APAIS in the same manner, the difference in the degree of anxiety assessed using the STAI and VAS was investigated between the patients who agreed to participate in the clinical study and those who did not (agreed group and disagreed group, respectively). After patients had completed the survey questionnaire, the degree of anxiety was compared based on the STAI and VAS data as a primary outcome according to the traits in the agreed 
and disagreed groups. The degree of anxiety was also compared according to patient sex, past history of operation, ASA physical status class, and education. For the secondary outcome, the patients ' understanding, feelings, and responses to the description of the clinical study related to participation according to the traits were compared between the two groups.

\section{Statistics}

The statistical process was carried out using Jandel SigmaStat ${ }^{\circledR}$ (version 4.0, Systat Software Inc., San Jose, CA, USA) and SPSS version 24.0 (IBM Corp., Armonk, NY, USA) for Windows. The normality of the categorical data from the two groups, such as the VAS and STAI values, was tested, and the data were then analyzed using the t-test and Mann-Whitney method. The independent variables of the nominal data, such as the difference depending on the sex, past history of operation, ASA physical status class, and education, were tested by performing the chisquare test and Fisher's exact test. When comparing the ratios between the two groups, a z-test and the Yates correction method were used. The significance level was $\mathrm{P}<0.05$ in all cases.

\section{Results}

Out of the 310 subjects whose questionnaires were included in the analysis, excluding the subjects with missing questionnaire responses from a total of 321 subjects, 272 subjects were in the agreed group (88\%) and 38 subjects were in the disagreed group (12\%). The number of male (female) subjects, average age of the subjects, number of patients with ASA class 1 and 2, number of patients who had a past history of operation, and level of education did not significantly differ between the agreed and disagreed groups (Table 1).

Comparison of personal traits according to the several variables in the agreed and disagreed groups showed no significant differences, with the exception of the item of education level (Table 2). Among the patients with a lower educational level (elementary, middle, and high school education), the number of blunters was 57 (79\%) and the number of monitors was 32 (59\%), indicating that the ratio of blunters was significantly higher $(\mathrm{P}=$ 0.026 , Table 2).

Table 1. Patient Characteristics are Presented for Agreed and Disagreed Group

\begin{tabular}{lccc}
\hline & $\begin{array}{c}\text { Agreed group } \\
(\mathrm{n}=272)\end{array}$ & $\begin{array}{c}\text { Disagreed group } \\
(\mathrm{n}=38)\end{array}$ & P value \\
\hline Sex & & & \\
M & $134(49.3)$ & $18(47.4)$ & 0.963 \\
F & $138(50.7)$ & $20(52.6)$ & 0.940 \\
Age & $44.0(33.0,51.0)$ & $37.5(29.0,47.0)$ & 0.060 \\
Op. Hx & & & \\
$\quad$ Yes & $137(50.4)$ & $20(52.6)$ & 0.930 \\
$\quad$ No & $135(49.6)$ & $18(47.4)$ & 0.946 \\
ASA PS & & & \\
$\quad$ 1 & $179(65.9)$ & $29(76.3)$ & 0.268 \\
2 & $93(34.2)$ & $9(23.7)$ & 0.789 \\
Education & & & \\
$\quad$ Low (E, M, H) & $186(68.4)$ & $20(52.6)$ & 0.081 \\
$\quad$ High (U) & $86(31.6)$ & $18(47.4)$ & 0.316 \\
\hline
\end{tabular}

Values are number of the patients (\%) or median (interquartile range). Op. Hx: operation history, ASA PS: American Society of Anesthesiologists physical status, E: elementary school, M: middle school, H: high school, U: university. Chi-square test and MannWhitney test were done for statistical analysis.

Table 2. Comparison of Personal Traits according to the Several Variables in the Both Agreed and Disagreed Group

\begin{tabular}{|c|c|c|c|c|c|c|}
\hline & \multicolumn{2}{|c|}{ Agreed group } & \multirow[b]{2}{*}{ P value } & \multicolumn{2}{|c|}{ Disagreed group } & \multirow[b]{2}{*}{$P$ value } \\
\hline & $\begin{array}{c}\text { Monitors } \\
\mathrm{n}=54 \\
(19.85)\end{array}$ & $\begin{array}{c}\text { Blunters } \\
\mathrm{n}=72 \\
(26.47)\end{array}$ & & $\begin{array}{c}\text { Monitors } \\
\mathrm{n}=4 \\
(10.53)\end{array}$ & $\begin{array}{c}\text { Blunters } \\
\mathrm{n}=13 \\
(34.21)\end{array}$ & \\
\hline \multicolumn{7}{|l|}{ Sex } \\
\hline M & $23(42.6)$ & $41(56.9)$ & 0.157 & $1(25.0)$ & $7(53.9)$ & 0.576 \\
\hline $\mathrm{F}$ & $31(57.4)$ & $31(43.1)$ & 0.379 & $3(75.0)$ & $6(46.2)$ & 0.912 \\
\hline \multicolumn{7}{|l|}{ Op. Hx } \\
\hline Yes & $31(57.4)$ & 35 (48.6) & 0.425 & $1(25.0)$ & $8(61.5)$ & 0.294 \\
\hline No & $23(42.6)$ & $37(51.4)$ & 0.691 & $3(75.0)$ & $5(38.5)$ & 0.785 \\
\hline \multicolumn{7}{|l|}{ ASA PS } \\
\hline 1 & $33(61.1)$ & $46(63.9)$ & 0.894 & $4(100)$ & $9(69.2)$ & 0.519 \\
\hline 2 & $21(38.9)$ & $26(36.1)$ & 0.910 & 0 & $4(30.8)$ & \\
\hline \multicolumn{7}{|l|}{ Education } \\
\hline Low $(\mathrm{E}, \mathrm{M}, \mathrm{H})$ & $32(59.3)$ & $57(79.2)^{*}$ & 0.026 & $2(50.0)$ & $7(53.9)$ & 1.000 \\
\hline High (U) & $22(40.7)$ & $15(20.8)$ & 0.360 & $2(50.0)$ & $6(46.2)$ & 0.470 \\
\hline
\end{tabular}

Values are number of the patients (\%). Op. Hx: operation history, ASA PS: American Society of Anesthesiologists Physical Status, E: elementary school, M: middle school, H: high school, U: university. Chi-square test, Fisher's exact test and z-test with Yates correction were done for statistical analysis. *Significantly higher than monitors in the agreed group. 
Only a small percentage of patients in the agreed group stated that they felt satisfaction or a sense of accomplishment, and all of the monitor and blunter types of patients in the disagreed group stated that they felt anxiety rather than a sense of accomplishment (Table 3 ). In the agreed group, the proportion of blunters who stated that the clinical study increased their anxiety was significantly higher than that of the monitors $(\mathrm{P}<0.001$, Table 3). The proportion of monitors who stated that the clinical study did not increase their anxiety was significantly higher than that of the blunters in the agreed group $(\mathrm{P}<0.001$, Table 3$)$.

In the agreed group, the average scores on the "usual STAI," representing the anxiety that the patients usually feel, were 24.6 \pm 6.7 and $21.9 \pm 7.0$ in the monitors and blunters, respectively (Table 3). The average scores on the "present STAI," representing the anxiety that the patients felt at the time of the survey in the agreed group, were $22.9 \pm 5.1$ and $20.8 \pm 5.3$ in the monitors and

Table 3. Comparison of the Patients' Anxiety Scale Measured by State Trait Anxiety Inventory and Visual Analogue Scale according to the Traits Classified by the Amsterdam Preoperative Anxiety and Information Scale in the Agreed and the Disagreed Group

\begin{tabular}{|c|c|c|c|c|c|c|}
\hline & \multicolumn{2}{|c|}{$\begin{array}{l}\text { Agreed group } \\
\quad(\mathrm{n}=272)\end{array}$} & \multirow{2}{*}{$\begin{array}{l}\text { P value } \\
(95 \% \text { CI })\end{array}$} & \multicolumn{2}{|c|}{$\begin{array}{l}\text { Disagreed group } \\
\quad(\mathrm{n}=38)\end{array}$} & \multirow{2}{*}{$P$ value } \\
\hline & $\begin{array}{c}\text { Monitors } \\
\mathrm{n}=54 \\
(19.85)\end{array}$ & $\begin{array}{c}\text { Blunters } \\
\mathrm{n}=72 \\
(26.47)\end{array}$ & & $\begin{array}{c}\text { Monitors } \\
\mathrm{n}=4 \\
(10.53)\end{array}$ & $\begin{array}{c}\text { Blunters } \\
\mathrm{n}=13 \\
(34.21)\end{array}$ & \\
\hline \multicolumn{7}{|l|}{ Feeling at request } \\
\hline Satisfied & $9(16.7)$ & $8(11.1)$ & $0.683(-0.277,0.377)$ & $0(0)$ & $0(0)$ & \\
\hline Anxiety, regret & $45(83.3)$ & $64(88.9)$ & $0.536(-0.190,0.070)$ & $4(100)$ & $13(100)$ & \\
\hline \multicolumn{7}{|l|}{ Anxiety } \\
\hline Yes & $5(9.3)$ & $10(13.9)^{*}$ & $<0.001(-0.162,-0.478)$ & & & \\
\hline No & $49(90.7)^{\dagger}$ & $62(86.1)$ & $<0.001(-1.016,-0.444)$ & & & \\
\hline Usual STAI & $24.6 \pm 6.7^{\dagger}$ & $21.9 \pm 7.0$ & 0.041 & $27.0 \pm 9.3$ & $24.0 \pm 6.3$ & 0.466 \\
\hline Present STAI & $22.9 \pm 5.1^{\dagger}$ & $20.8 \pm 5.3$ & 0.017 & $22.8 \pm 3.6$ & $19.9 \pm 4.4$ & 0.250 \\
\hline VAS & $45.2 \pm 25.6^{\dagger}$ & $30.5 \pm 25.4$ & 0.001 & $52.5 \pm 33.0$ & $39.2 \pm 28.6$ & 0.445 \\
\hline
\end{tabular}

Values are mean \pm SD or number of the patients (\%). STAI: state trait anxiety inventory, VAS: visual analogue scale. ${ }^{*}$ Significantly higher than monitors in the agreed group. ${ }^{\dagger}$ Significantly higher than blunters in the agreed group. Z-test with Yates correction was done for statistical analysis of the feeling and presence of anxiety. T-test and Mann-Whitney rank sum test were done for statistical analysis of the anxiety scale.

Table 4. Comparison of Patient's Understanding, Feelings and Responses to the Description of the Clinical Study Participation according to the Traits Classified by the Amsterdam Preoperative Anxiety and Information Scale in the Agreed and the Disagreed Group

\begin{tabular}{|c|c|c|c|c|c|c|}
\hline & \multicolumn{2}{|c|}{$\begin{array}{l}\text { Agreed group } \\
\quad(\mathrm{n}=272)\end{array}$} & \multirow{2}{*}{$\begin{array}{l}\text { P value } \\
(95 \% \mathrm{CI})\end{array}$} & \multicolumn{2}{|c|}{$\begin{array}{l}\text { Disagreed group } \\
\quad(\mathrm{n}=38)\end{array}$} & \multirow{2}{*}{$\begin{array}{c}\text { P value } \\
(95 \% \mathrm{CI})\end{array}$} \\
\hline & $\begin{array}{c}\text { Monitors } \\
\mathrm{n}=54 \\
(19.85)\end{array}$ & $\begin{array}{c}\text { Blunters } \\
\mathrm{n}=72 \\
(26.47)\end{array}$ & & $\begin{array}{c}\text { Monitors } \\
\mathrm{n}=4 \\
(10.53)\end{array}$ & $\begin{array}{c}\text { Blunters } \\
\mathrm{n}=13(34.21)\end{array}$ & \\
\hline \multicolumn{7}{|l|}{ Understand (scale) } \\
\hline Understand & $29(53.7)$ & $28(38.9)$ & $0.427(-0.119,0.399)$ & $2(50.0)$ & $8(61.5)$ & $0.620(-0.880,0.640)$ \\
\hline Do not understand & $25(46.3)$ & $44(61.1)$ & $0.340(-0.394,0.093)$ & $2(50.0)$ & $5(38.4)$ & $0.577(-0.688,0.928)$ \\
\hline \multicolumn{7}{|l|}{ Research ethics } \\
\hline Ethical & $12(22.2)$ & $10(13.9)$ & $0.944(-0.245,0.405)$ & $1(25.0)$ & $5(38.5)$ & $0.371(-1.160,0.900)$ \\
\hline Questionable & $42(77.8)$ & $62(86.1)$ & $0.426(-0.228,0.067)$ & $3(75.0)$ & $8(61.5)$ & $0.837(-0.818,0.498)$ \\
\hline \multicolumn{7}{|l|}{ Reason for agreement } \\
\hline Medical growth & $37(68.5)$ & $43(59.7)$ & $0.546(-0.121,0.301)$ & & & \\
\hline Good medical benefit & $15(27.8)$ & $18(25.0)$ & $0.840(-0.272,0.332)$ & & & \\
\hline \multicolumn{7}{|l|}{ Participate } \\
\hline Full understand & & & & $1(25.0)$ & $8(61.5)$ & $0.713(-1.396,0.656)$ \\
\hline No anxiety & & & & $2(50.0)$ & $4(30.8)$ & $0.659(-0.631,1.011)$ \\
\hline No Cx & & & & $3(75.0)$ & $6(46.2)$ & $0.909(-0.398,0.978)$ \\
\hline \multicolumn{7}{|l|}{ If economic gain } \\
\hline Participate & & & & $1(25.0)$ & $2(15.4)$ & $0.170(-0.829,1.029)$ \\
\hline Do not participate & & & & $3(75.0)$ & $6(46.2)$ & $0.909(-0.398,0.978)$ \\
\hline
\end{tabular}

Values are number of the patients (\%). Cx: complication. Z-test with Yates correction was done for statistical analysis. 
blunters, respectively (Table 3 ). The VAS scores of the agreed group were $45.2 \pm 25.6$ and $30.5 \pm 25.4$ in the monitors and blunters, respectively (Table 3 ). The degree of anxiety measured by "usual, present STAI" and VAS in the monitors who agreed to participate in the clinical study was significantly higher than that of the blunters ( $\mathrm{P}=0.041$ for the "usual STAI," 0.017 for the "present STAI," and 0.001 for VAS, respectively, Table 3). In the disagreed group, the average "usual and present STAI" scores and VAS were not significantly different in the monitors and blunters (Table 3). The degree of anxiety measured by "usual STAI" was not significant compared to that of "present STAI" according to the traits in both groups (data not shown).

The patients in both groups had a somewhat good understanding of the clinical study, regardless of their agreement to participate, but many of them had a negative point of view toward the clinical trials conducted in South Korea (Table 4). In the agreed group, $69 \%$ of the monitors and $60 \%$ of the blunters stated that they wanted to contribute to the advancement of medicine (Table 4). However, agreement was not significantly dependent on the temperament of the patients (Table 4). The patients in the disagreed group stated that they decided not to participate in the clinical study because of complications or anxiety. They would participate if the clinical study was sufficiently understood (53.9\%), if they did not feel anxiety (35.3\%), and if the absence of adverse effects (53.9\%) was confirmed (Table 4). The economic compensation involved in participation in the clinical study had no effect on the patients' decision regarding participation, regardless of temperament (Table 4).

\section{Discussion}

Various subjective or objective methods have been developed to assess preoperative anxiety. The most frequently used subjective, self-rating method is the STAI scale developed by Grös et al. [7]. Since the STAI consists of about 40 items to measure anxiety considering patients' temperament and situation, it is too timeconsuming to be used in actual clinical settings. According to Miller [8,9], patients may be classified by the Miller Behavioral Style Scale (MBSS) with reference to the behavior pattern when confronted with four stressful situations into one group of patients who want to learn about the stressful situations in order to reduce anxiety, and another group of patients who do not want to learn about the stressful situations. Providing a detailed preoperative explanation of surgery or anesthesia to patients who, by temperament, do not want to learn about the surgery or anesthesia may increase rather than decrease their anxiety. However, a patient's temperament is difficult to ascertain through a short preoperative interview in the actual clinical setting. In addition, the details of the MBSS make it complicated to apply to a patient before an elective surgery. Moerman et al. [5] have developed the APAIS as a new preoperative anxiety self-rating method through which a patient's anxiety and temperament may be determined in a simple manner in busy clinical settings. The APAIS may be used with additional explanation as it is adjusted to a preoperative situation. In addition, as the APAIS includes a smaller number of questions, it may be implemented in a short period of time. However, since patients may not distinctively differentiate the fear of anesthesia from the fear of surgery, the preoperative anxiety assessed using the APAIS is extensive, not confined to each type of fear.

In a study conducted with children, Harth and Thong [10] found that a higher level of education is required to accurately understand the purposes and methods of a clinical study and that the psycho-sociological characteristics of the caregivers had a significant effect on the rate of participation in clinical research. Harth et al. [10] also reported that the degree of anxiety and the rate of study participation were higher in introspective and less-educated caregivers with a lower level of social confidence. The present study also showed that the proportion of patients in the agreed group was higher (68\%) among patients with a low level of education and lower (32\%) among patients with a higher level of education (Table 1). In the study by Harth and Thong [10], a high percentage of patients showed an increased level of anxiety and responded that they did not understand the clinical research because the interview was performed preoperatively in the waiting room during a short period of time. Based on clinical trials conducted in African American patients with prostate cancer, Robinson et al. [11] reported that patients with more knowledge and information about clinical trials showed a higher participation rate, suggesting that the advantages of clinical trials may be positively presented to patients. Robinson et al. [11] also reported that the participation rate was high among patients who were old or who had a moderate or higher level of education, from a socioeconomic point of view. In the present study, in contrast to the prediction that the participation rate might be higher in the monitors with a stronger desire for information than in the blunters, the participation rate was significantly higher in the blunters with a lower education level ( $\mathrm{P}$ $=0.026$, Table 2 ). This difference is presumed to be related to the large differences in the health insurance system and medical expenses between the US and South Korea. Fair sharing of healthcare expenses and reasonable benefit in kind are key functions of the national health insurance scheme in South Korea. The health insurance system is well established, and covers the whole population. As the study of Robinson et al. [11] was conducted considering only the socioeconomic aspects, not the temperament of the patients, further studies may need to be conducted in this regard.

The patients made the decision regarding participation when they did not sufficiently understand the clinical research, 
indicating that the decision was not based on adequate understanding and voluntary agreement. In the present study, on the other hand, the patients made the decision with regard to participation after they were given sufficient explanation from an anesthesia resident on the day before the surgery with adequate time for consideration, and thus the patients well understood the clinical study described in detail in the survey questionnaire.

Tait et al. [12] reported that about $12 \%$ of patients who declined to participate in a clinical study stated that they had insufficient time for decision-making and that about 3\% of the patients felt that they were coerced into participating. In the present study, the clinical study described in the survey questionnaire was explained to the patients not on the day of surgery, when the patients might feel anxious, but on the day before the surgery, so that the patients could learn about the clinical study in a comfortable setting. All information that could identify a patient was removed. The patients were requested to respond to the survey items immediately after making the decision regarding participation to eliminate external factors to the greatest possible extent. Mingus et al. [13] acquired subjects' participation after providing sufficient time to consider the decision (20 to 30 minutes), excluding all coercive factors.

Salomons et al. [14] reported that the likelihood of participating in a clinical trial was higher among patients who had a past history of operation, young patients, patients with a systemic disease, patients with another type of pain, patients who had a long period of time before surgery, and tall patients. Salomons et al. [14] also reported that the participation ratio was low if the study method was extraordinary. In the present study, no significant difference was found in the participation rate between patients with a past history of operation and patients without a past history of operation (Table 2).

The anxiety felt by the subjects in both groups was measured by the anxiety measurement method developed by Grös et al. [7]. Even though a higher proportion of the blunters than of the monitors expressed anxiety regarding the clinical study $(\mathrm{P}<0.001$, Table 3), the anxiety felt by subjects was significantly higher in the monitors than in the blunters on the "usual, present STAI" scores and VAS scores for patients in the agreed group (Table 3). However, no significant differences were observed in the disagreed group (Table 3). It is not clearly known whether these methods of measuring anxiety had an effect on the decision regarding participation in the clinical study. In addition, on the basis of the finding that explanation of the clinical study significantly increases anxiety in the blunters in comparison with the monitors in the disagreed group, the proportion of monitors who participate in the clinical study may be further increased if the monitors have a full understanding of the clinical study (Table 4).

In the present study, $46 \%$ of the monitors and $61 \%$ of the blunters in the agreed group responded that they did not un- derstand the clinical study well, as did $50 \%$ of the monitors and $38 \%$ of the blunters in the disagreed group (Table 4 ). However, on the basis of the finding that explanation of the clinical study significantly increased anxiety in the blunters, the proportion of blunters who participate in the clinical study may be decreased if the blunters obtain a full understanding of the clinical study $(\mathrm{P}<0.001$, Table 4). With regard to the reasons for agreement to participate, $69 \%$ of the monitors and $60 \%$ of the blunters stated that they wanted to contribute to the advancement of medicine, while $28 \%$ of the monitors and $25 \%$ of the blunters stated that they expected to receive medical service of good quality (Table 4).

Sammons et al. [15] reported a participation rate of $59 \%$. The participation rate in the present study $87.8 \%$, which was higher than that in study conducted by Sammons et al. [15]. The rate of refusal to participate was low in the present study, probably because the specific information regarding the clinical study was easily and clearly understood by the patients through the use of the questionnaire. The purpose of the clinical study was to compare the results of two different anesthetic methods. When it was explained to the patients that both of the anesthetic methods, intravenous anesthesia and inhalation anesthesia, were the methods normally used by the hospital, the patients readily agreed to participate in the clinical study, recognizing that the study was almost risk-free. It was also explained that the intravenous anesthetic, propofol, is a drug that has been used in South Korea for a long time, which helped the patients obtain a better understanding of the study and to make the decision regarding participation. However, the information and data for the complete objectors, who refused not only to participate in the study but also to participate in the survey, were not available. Therefore, the rate of participation should have been calculated by considering the complete objectors from the initiation of the survey.

It is also important that a doctor who has no involvement with the implementation of preoperative treatment or anesthesia is employed to obtain consent regarding participation so that the patients may not feel psychologically pressured with regard to participation. The result that $75 \%$ of the monitors and $46 \%$ of the blunters responded that they would not participate in the clinical study even if they might economically benefit from the study indicated that economic compensation is not an effective compensation measure because the health insurance system has been well established and medical expenses are low in South Korea (Table 4).

The results of the present study showed that both the patients who agreed to participate in the clinical study and those who disagreed experienced psychological burdens for various reasons. To decrease the psychological burden of the patients, researchers should allow at least 20 minutes for review of the questionnaire, and should provide a detailed explanation of a 
clinical study in a relaxed and noncoercive environment [13]. In particular, making it clear that a patient who is requested to participate in a clinical study may refuse participation without any disadvantages may reduce the psychological burden that patients may experience. However, the temperament of a patient may be quickly investigated in advance to allow selection of a different approach, such as not providing detailed explanation of clinical research to a patient with a blunter type of temperament who may experience increased rather than decreased anxiety with such an explanation.

There are several limitations of the current study. First, this survey was provided to patients enrolled to receive one of two low-risk anesthesia techniques. The setting of the clinical study may potentially influence a subject's comfort level with the provision of anesthesia. Factors such as the experience of the individual research project (high- or moderate-risk study) may significantly impact responses. Second, given the small number of refusal responses reported in this study, it is unlikely that a significant difference would have been observed between the two groups. Third, the survey tool developed by our author group has not been formally validated. Finally, data were not collected for patients who did not return the surveys. This is a potential source of selection bias since the responses may have differed in those not returning surveys.

In summary, both traits of the patients who agreed and disagreed to participate in a clinical study were influenced by psychological burdens. The anxiety of the monitors who agreed to participate in a clinical study related to anesthesia was significantly higher than that of the blunters. Factors relevant to participation should be identified. In addition to temperament, the education level of the patients affects the rate of participation in a clinical study. Although the situations of patients may not be schematized using a single scale, a study plan should be established by obtaining consent from patients in the best way possible. Obtaining consent for participation by quickly understanding patients' temperament with a convenient method, and considering factors that may reduce the participation rate, will be required.

\section{ORCID}

Jae Hoon Oh, http://orcid.org/0000-0003-2129-2033

Woo Jong Shin, http://orcid.org/0000-0002-3786-2267

\section{References}

1. Boker A, Brownell L, Donen N. The Amsterdam preoperative anxiety and information scale provides a simple and reliable measure of preoperative anxiety. Can J Anaesth 2002; 49: 792-8.

2. Domar AD, Everett LL, Keller MG. Preoperative anxiety: is it a predictable entity? Anesth Analg 1989; 69: 763-7.

3. Davidson AJ, Shrivastava PP, Jamsen K, Huang GH, Czarnecki C, Gibson MA, et al. Risk factors for anxiety at induction of anesthesia in children: a prospective cohort study. Paediatr Anaesth 2006; 16: 919-27.

4. Murphy GS, Szokol JW, Avram MJ, Greenberg SB, Shear TD, Vender JS, et al. Consent for anesthesia clinical trials on the day of surgery: patient attitudes and perceptions. Anesthesiology 2016; 124: 1246-55.

5. Moerman N, van Dam FS, Muller MJ, Oosting H. The Amsterdam Preoperative Anxiety and Information Scale (APAIS). Anesth Analg 1996; 82: 445-51.

6. Voss U, Kolling T, Heidenreich T. Role of monitoring and blunting coping styles in primary insomnia. Psychosom Med 2006; 68: 110-5.

7. Grös DF, Antony MM, Simms LJ, McCabe RE. Psychometric properties of the State-Trait Inventory for Cognitive and Somatic Anxiety (STICSA): comparison to the State-Trait Anxiety Inventory (STAI). Psychol Assess 2007; 19: 369-81.

8. Miller SM. Coping with impending stress: psychophysiological and cognitive correlates of choice. Psychophysiology 1979; 16: 572-81.

9. Miller SM. Monitoring and blunting: validation of a questionnaire to assess styles of information seeking under threat. J Pers Soc Psychol 1987; 52: 345-53.

10. Harth SC, Thong YH. Sociodemographic and motivational characteristics of parents who volunteer their children for clinical research: a controlled study. BMJ 1990; 300: 1372-5.

11. Robinson SB, Ashley M, Haynes MA. Attitude of African-Americans regarding prostate cancer clinical trials. J Community Health 1996; 21: 77-87.

12. Tait AR, Voepel-Lewis T, Siewert M, Malviya S. Factors that influence parents' decisions to consent to their child's participation in clinical anesthesia research. Anesth Analg 1998; 86: 50-3.

13. Mingus ML, Levitan SA, Bradford CN, Eisenkraft JB. Surgical patients' attitudes regarding participation in clinical anesthesia research. Anesth Analg 1996; 82: 332-7.

14. Salomons TV, Wowk AA, Fanning A, Chan VW, Katz J. Factors associated with refusal to enter a clinical trial: epidural anesthesia is a deterrent to participation. Can J Anaesth 2002; 49: 583-7.

15. Sammons HM, Atkinson M, Choonara I, Stephenson T. What motivates British parents to consent for research? A questionnaire study. BMC Pediatr 2007; 7: 12. 


\section{Appendix}

$\star$ Usual STAI

\begin{tabular}{|c|c|c|c|c|}
\hline Questions & $\begin{array}{c}\text { Not at all } \\
0\end{array}$ & $\begin{array}{c}\text { A little } \\
1\end{array}$ & $\begin{array}{c}\text { Usually } \\
2\end{array}$ & $\begin{array}{c}\text { Very much } \\
3\end{array}$ \\
\hline 1. I feel good. & & & & \\
\hline 2. I get tired easily. & & & & \\
\hline 3. I want to cry. & & & & \\
\hline 4. I want to be as happy as others. & & & & \\
\hline 5. I fail because I cannot make up my mind quickly. & & & & \\
\hline 6. I am set in my heart. & & & & \\
\hline 7. I am calm, cool, and collected. & & & & \\
\hline 8. I do not think I can overcome too many problems. & & & & \\
\hline 9. I worry too much about trivial things. & & & & \\
\hline 10. I am happy. & & & & \\
\hline 11. I think hard about everything. & & & & \\
\hline 12. I lack confidence. & & & & \\
\hline 13. I am relieved. & & & & \\
\hline 14. I try to avoid crises or difficulties. & & & & \\
\hline 15. I am depressed. & & & & \\
\hline 16. I am satisfied. & & & & \\
\hline 17. Trivial thoughts bother me. & & & & \\
\hline 18. I take disappointments so keenly that I can't get them out of my mind. & & & & \\
\hline 19. I am a steady person. & & & & \\
\hline ed about the troubles and concerns of the present. & & & & \\
\hline
\end{tabular}




\section{Patient's Temperament}

Date: $\quad$ Male, Female $\quad$ Age $(\quad$ ) $\quad \operatorname{Height/Weight~}(\quad / \quad)$

Diagnosis $\quad$ ASA ( )

Operation

Patient Controlled Analgesia ( )

Underlying disease; DM, H/T, Tuberculosis, Asthma, Allergy,

etc. (

)

Education $(1,2,3,4)$ Past general anesthesia history: yes ( ) none ( )

Q1. About anesthesia

A. I am worried about the operation:
1) Not at all
2) A little
3) Usually
4) Very much
5) Endlessly

B. The operation is on my mind continually:
1) Not at all
2) A little
3) Usually
4) Very much
5) Endlessly

C. I would like to know as much as possible about the operation:
1) Do not want to know
2) Want to know a little
3) Want to know usually
4) Want to know much
5) Want to know very much

Q2. About operation

A. I am worried about the operation:
1) Not at all
2) A little
3) Usually
4) Very much
5) Endlessly

B. The operation is on my mind continually:
1) Not at all
2) A little
3) Usually
4) Very much
5) Endlessly

C. I would like to know as much as possible about the operation:
1) Do not want to know
2) Want to know a little
3) Want to know usually
4) Want to know much
5) Want to know very much
Score Q1C + Q2C ( $\quad$ )
Monitors = Score Q1C + Q2C $\geq 8$
Blunters = Score Q1C $+\mathrm{Q} 2 \mathrm{C} \leq 4$ 


\section{Study Explanation}

Major anesthetics; volatile anesthetics $/ \mathrm{N}_{2} \mathrm{O}(\quad)$ intravenous/remifentanil ( $\quad$ )

Muscle relaxant; esmeron ( $\quad$ ) mg, vecaron ( $\quad$ ) mg, atracurium ( $\quad) \mathrm{mg}$

Operation duration ( ) min, anesthesia ( ) min, extubation after anesthesia ( ) min

Anes machine; Avance ( $\quad$ ), Aestiva ( Excel ( )

Vaporizer ( No $\quad$ ), operation room number $\quad$ ), room temperature $(\quad){ }^{\circ} \mathrm{C}$

Pre-Op vaporizer weight ( ) gm,

Post-Op vaporizer weight ( ) gm,

Weight difference ( $)$ gm

Consumption; volatile anesthetics ( ) ml,

intravenous anesthetics ( $)$ ml, remifentanil ( $) \mu g$
etc. (

Did you understand the content of the clinical studies described above?

1. Very well

2. Generally

3. Usually

4. I did not understand it well

5. I do not know

What do you think about clinical trials in Korea?

1. Clinical trials are carried out responsibly and ethically

2. Clinical trials are not carried out responsibly and ethically

3. I do not know

Have you ever been involved in medical clinical trials in the past?

1. Yes 2 No

How did you feel when you were asked to participate in clinical research?
1. Satisfaction
2. Achievement
3. Confidence
4. Anxiety
5. Regret
6. No feelings
1. Yes
2. No 


\section{$\star$ Check the degree of anxiety right now at this moment}

$\mathbf{0}$

Agreed patient

Please select the reason for your participation in the clinical study.

(Multiple selection possible)

1. Due to the idea of contributing to the development of medical care.

2. You will receive better quality health care during surgery and anesthesia.

3. Because there is no anxiety about the effects and side effects of new anesthetics.

4. Because you can revoke your consent at any time.

5. I am afraid that it is difficult to reject the request to participate and that there is a disadvantage if I refuse.

6. If you have any other reason, please write below.

(

If you could obtain the following information, what would you like to know about?

1. Explanation of the anesthetic time of each anesthetic method.

2. Explanation of the advantages and disadvantages of each anesthetic method and the description of the expected effects and side effects.

3. Explanation of the pain and analgesics after each anesthetic method.

4. Explanation of the most dangerous and common complications of each anesthetic method.

5. Explanation of whether you can withdraw consent at any time after you agree to participate.

6. Explanation of disadvantages of not agreeing to participate.

7. I do not want to know.

How do you feel when you take part in an anesthetic clinical study with a new drug?
1. Very worried
2. A little worried
3. Not worried
4. I do not know

Are you worried about surgery?
1. Very worried
2. A little worried
3. Not worried
4. I do not know

If you have any concerns about the surgery, please specify them. ( 
$\star$ Present STAI

\begin{tabular}{|c|c|c|c|c|}
\hline Question & $\begin{array}{c}\text { Not at all } \\
0\end{array}$ & $\begin{array}{c}\text { A little } \\
1\end{array}$ & $\begin{array}{c}\text { Usually } \\
2\end{array}$ & $\begin{array}{c}\text { Very much } \\
3\end{array}$ \\
\hline 1. I feel good. & & & & \\
\hline 2. I get tired easily. & & & & \\
\hline 3. I want to cry. & & & & \\
\hline 4. I want to be as happy as others. & & & & \\
\hline 5. I fail because I cannot make up my mind quickly. & & & & \\
\hline 6. I am set in my heart. & & & & \\
\hline 7. I am calm, cool, and collected. & & & & \\
\hline 8. I do not think I can overcome too many problems. & & & & \\
\hline 9. I worry too much about trivial things. & & & & \\
\hline 10. I am happy. & & & & \\
\hline 11. I think hard about everything. & & & & \\
\hline 12. I lack confidence. & & & & \\
\hline 13. I am relieved. & & & & \\
\hline 14. I try to avoid crises or difficulties. & & & & \\
\hline 15. I am depressed. & & & & \\
\hline 16. I am satisfied. & & & & \\
\hline 17. Trivial thoughts bother me. & & & & \\
\hline 18. I take disappointments so keenly that I can't get them out of my mind. & & & & \\
\hline 19. I am a steady person. & & & & \\
\hline rried about the troubles and concerns of the present & & & & \\
\hline
\end{tabular}




\section{Disagreed patient}

Please select the reason you did not agree to participate in the clinical study.

(Multiple selection possible)

1. The risks and side effects of surgery and anesthesia.

2. Anxiety about the effects and side effects of each anesthetic agent.

3. Fewer benefits for participating in clinical studies.

4. Could not understand the content of the clinical study.

5. The method of clinical research and the medical staff are not credible.

6. No economic benefits (free anesthesia, etc.).

7. List any other reasons you may have (bad health, moral, religious reasons, etc.).

(

Do you think you will not receive good quality of surgery and anesthesia when you refuse to participate?
1. Yes
2. No

Under which of the following circumstances would you agree to participate in clinical studies?

(Multiple selection possible)

1. Detailed understanding of the clinical trial.

2. When there is no anxiety about the clinical trial.

3. If it is confirmed that there is no adverse effect of the clinical trial.

4. Economic benefits (no charge for anesthesia, etc.).

5. If there is no compulsion to participate in clinical trials.

What if you receive the following economic benefits (such as free anesthesia)?

1. will definitely participate

2. may agree to participate

3. will never participate

4. I do not know 
$\star$ Present STAI

\begin{tabular}{|c|c|c|c|c|}
\hline Question & $\begin{array}{c}\text { Not at all } \\
0\end{array}$ & $\begin{array}{c}\text { A little } \\
1\end{array}$ & $\begin{array}{c}\text { Usually } \\
2\end{array}$ & $\begin{array}{c}\text { Very much } \\
3\end{array}$ \\
\hline \multicolumn{5}{|l|}{ 1. I feel good. } \\
\hline \multicolumn{5}{|l|}{ 2. I get tired easily. } \\
\hline \multicolumn{5}{|l|}{ 3. I want to cry. } \\
\hline \multicolumn{5}{|l|}{ 4. I want to be as happy as others. } \\
\hline \multicolumn{5}{|c|}{ 5. I fail because I cannot make up my mind quickly. } \\
\hline \multicolumn{5}{|l|}{ 6. I am set in my heart. } \\
\hline \multicolumn{5}{|l|}{ 7. I am calm, cool, and collected. } \\
\hline \multicolumn{5}{|c|}{ 8. I do not think I can overcome too many problems. } \\
\hline \multicolumn{5}{|l|}{ 9. I worry too much about trivial things. } \\
\hline \multicolumn{5}{|l|}{ 10. I am happy. } \\
\hline \multicolumn{5}{|l|}{ 11. I think hard about everything. } \\
\hline \multicolumn{5}{|l|}{ 12. I lack confidence. } \\
\hline \multicolumn{5}{|l|}{ 13. I am relieved. } \\
\hline \multicolumn{5}{|l|}{ 14. I try to avoid crises or difficulties. } \\
\hline \multicolumn{5}{|l|}{ 15. I am depressed. } \\
\hline \multicolumn{5}{|l|}{ 16. I am satisfied. } \\
\hline \multicolumn{5}{|l|}{ 17. Trivial thoughts bother me. } \\
\hline \multicolumn{5}{|c|}{ 18. I take disappointments so keenly that I can't get them out of my mind. } \\
\hline 19. I am a steady person. & & & & \\
\hline
\end{tabular}

